\title{
Liquidez Internacional e Formação Bruta de Capital Fixo: Evidências Econométricas para as Economias Desenvolvidas e em Desenvolvimento
}

\section{International Liquidity and Gross Fixed Capital Formation: Econometric Evidence for Developed and Developing Economies}

Daniela Almeida Raposo Torres*

Marco Flávio da Cunha Resende**

\begin{abstract}
Resumo: O objetivo deste artigo consiste em realizar uma investigação empírica sobre a relevância da liquidez internacional na determinação do investimento. Particularmente, é investigado se os efeitos das oscilações da liquidez internacional sobre o investimento são distintos quando se considera o grupo das economias desenvolvidas e o grupo das economias em desenvolvimento, cujo sistema nacional de inovação (SI) apresenta menor desenvolvimento relativo. Tal análise é realizada com base na estimação de um modelo de investimento com dados em painel, segundo o método panel corrected standard errors (PCSE). Esse modelo apresenta como substrato teórico a abordagem pós-keynesiana. Os resultados confirmam que, nas economias em desenvolvimento, as oscilações do investimento são mais aderentes às variações da liquidez internacional do que nas economias desenvolvidas.
\end{abstract}

Palavras-chave: Liquidez internacional. Sistema nacional de inovações. Investimento.

\begin{abstract}
This paper consists of empirical research on the relevance of international liquidity in determining investment. Particularly, we tests if international liquidity effects on investment in developed countries is different from those in developing ones, where National Innovation System (SI) is not relatively developed. The analysis is done by an econometric estimation using the panel corrected standard errors (PCSE) method, which is adequate to deal with panel data. This model presents theoretical background as the post Keynesian approach. The results confirm that in developing economies fluctuations in investment are more dependent on international liquidity cycle when compared to developed countries.
\end{abstract}

Keywords: International liquidity. National innovation system. Investment.

JEL Classification: O40; O43.

* Doutora em Economia pela Universidade Federal de Minas Gerais (UFMG). Professora do Departamento de Economia da Universidade Federal de São João del Rei (UFSJ). E-mail: daniraposo@ufsj.edu.br

* * Doutor em Economia pela UnB. Pós-doutor em Economia pela Universidade de Cambridge. Professor associado do Centro de Desenvolvimento e Planejamento Regional (Cedeplar) e da Universidade Federal de Minas Gerais (UFMG). Bolsista de produtividade do CNPq. E-mail: resende@ cedeplar.ufmg.br 


\section{Introdução}

O sistema financeiro internacional não é neutro, afetando o crescimento das economias de modo desigual (DOW, 1993). Paula e Alves Júnior (1999), Arestis e Glickman (2002) e Resende e Amado (2007) argumentam, com base na abordagem minskyana de instabilidade financeira, que o sistema financeiro internacional é uma das variáveis relevantes na explicação dos ciclos das economias, em particular das economias em desenvolvimento. No entanto, na literatura evolucionária o Sistema Nacional de Inovações (SI) é crucial para o progresso tecnológico e ganhos de produtividade. Segundo essa literatura, o desenvolvimento do SI eleva a competitividade e reduz a vulnerabilidade externa da economia (FREEMAN, 1995; RAPOSO, 2009).

Baseando-se nas abordagens pós-keynesiana e evolucionária, Resende (2005) e Amado, Resende e Jayme Júnior (2007) argumentam que o grau de desenvolvimento relativo do SI, ao afetar a competitividade e a vulnerabilidade externa da economia, condiciona o comportamento do sistema financeiro internacional em relação a essa economia. Desse modo, os ciclos das economias com menor desenvolvimento relativo de seus SIs (economias em desenvolvimento) seriam mais sensíveis aos ciclos do sistema financeiro internacional. Portanto, o investimento e o crescimento dessas economias seriam função, entre outros fatores, do grau de desenvolvimento relativo do seu SI e dos ciclos de liquidez internacional.

O propósito deste artigo é desenvolver e estimar um modelo de investimento para testar a hipótese de que a formação bruta de capital fixo (FBKF) nas economias em desenvolvimento é mais aderente aos ciclos de liquidez internacional em relação à FBKF nas economias desenvolvidas. Argumenta-se que economias cujo SI é pouco desenvolvido e com deficiências em seu sistema financeiro sofrem restrições para seu crescimento, passando a depender da liquidez internacional para viabilizá-lo. As informações relevantes para este estudo serão agrupadas para o conjunto de 23 países desenvolvidos e em desenvolvimento. Será adotada uma metodologia de dados de painel para o período 1970-2006.

O artigo está organizado em quatro seções, incluída esta introdução. Na seção 2, propõe-se um modelo de investimento de inspiração pós-keynesiana. Na seção 3, tal modelo é estimado por meio de dados em painel. O modelo de investimento especificado incorpora a liquidez internacional e o SI como variáveis explicativas relevantes. A quarta seção destina-se às considerações finais do trabalho. 


\section{Os Determinantes do Investimento: uma Proposta de Cunho Pós-Keynesiano}

A literatura teórica e empírica sobre os determinantes do investimento assenta-se sobre diversas escolas do pensamento econômico, sendo possível identificar seis formulações sobre a função investimento agregado, a saber: o modelo keynesiano, o modelo do acelerador dos investimentos, o modelo do acelerador flexível, o modelo neoclássico do investimento, o modelo do investimento privado nos países em desenvolvimento e os modelos baseados na teoria neoclássica dos microfundamentos do investimento. ${ }^{1}$ Em geral, todos os modelos (teóricos e empíricos) supõem que o investimento está correlacionado com uma ou mais das seguintes variáveis: produto agregado e/ou grau de utilização da capacidade produtiva da economia; disponibilidade de crédito; taxa de juros real; grau de incerteza - em geral, representado pelas oscilações do nível de preços ou da taxa de câmbio; taxa de câmbio real; dívida externa/PIB; investimento do setor público; e carga tributária. Tais modelos "[...] permitem uma miríade de sofisticações não triviais e essencialmente inconclusivas" (SANTOS; PIRES, 2007, p. 9). Com relação aos resultados empíricos, as estimações desses modelos por diversos autores apresentam resultados muitas vezes pouco satisfatórios no que se refere à explicação do investimento.

A função investimento desenvolvida neste artigo tem como substrato teórico a literatura pós-keynesiana. Sua contribuição é desenvolver e estimar com base na escola pós-keynesiana um modelo de investimento para testar os efeitos dos ciclos de liquidez internacional sobre o investimento nas economias desenvolvidas e em desenvolvimento. ${ }^{2}$

Não obstante o modelo do acelerador do investimento esteja entre aqueles que produzem o melhor ajustamento dos dados (SACHS; LARRAIN, 2000), ${ }^{3}$ tal modelo apresenta uma série de deficiências quando interpretado à luz da teoria pós-keynesiana. Esse modelo negligencia variáveis relevantes, como custo do capital, rentabilidade e expectativas. No que se refere a estas variáveis relevantes

1 Conforme Santos e Pires (2007, p. 9), há um amplo reconhecimento na literatura de que os modelos tradicionais se ajustam aos dados muito melhor do que modelos baseados em microfundamentos "modernos".

2 Por fugir ao escopo deste artigo e por uma questão de espaço, não será feita a discussão sobre os modelos de investimento das diversas escolas do pensamento, como também não será feito o confronto de seus postulados, argumentos teóricos e resultados empíricos. Para maiores detalhes sobre os citados modelos, ver Servén e Solimano (1993), Studart (1992), Pelicioni e Resende (2009), Frischtak e Cavalcanti (2005), Chirinko (1993), Caballero (1999), Melo e Rodrigues Júnior (1998), Santos e Pires (2007), Boucekine e Cruz (2006), Alves e Luporini (2008, 2007), Ronci (1991), Greene e Villanueva (1991), Rocha e Teixeira (1996), Jacinto e Ribeiro (1998), Ribeiro e Teixeira (2001) e Cardoso (1992).

3 Para mais detalhes sobre esse ponto, ver Melo e Rodrigues Júnior (1998, p. 10). 
no referencial pós-keynesiano a decisão de investir é tomada com base na comparação entre a eficiência marginal do capital e a taxa de juros (KEYNES, 1983). Assim, as expectativas dos empresários com relação ao retorno do investimento desempenham papel central nas decisões de investir.

Ademais, o modelo do acelerador do investimento e os demais modelos teóricos e empíricos estabelecidos na literatura não contemplam os efeitos dos ciclos do sistema financeiro internacional sobre o investimento agregado das economias. Todavia, Dow (1987, 1986), Dow (1993, p. 171-176), Minsky (1994) e Amado (2003) demonstram que os ciclos do sistema financeiro internacional e seu comportamento tipicamente minskyano são relevantes para explicar os ciclos das economias, em particular das economias em desenvolvimento. Além dos trabalhos dos autores pós-keynesianos, há também aqueles que seguiram a tradição cepalina e kaldoriana, ${ }^{4}$ na qual o crescimento das economias em desenvolvimento seria restringido pelo balanço de pagamentos. Tais trabalhos apontam, novamente, para o papel dos ciclos do sistema financeiro internacional no estímulo ao investimento e ao crescimento das economias em desenvolvimento.

Portanto, com base na literatura pós-keynesiana, será desenvolvido a seguir um modelo de investimento que supere as limitações anteriormente apontadas. Pretende-se desenvolver e estimar uma equação de investimento agregado para verificar a hipótese de que a FBKF nas economias em desenvolvimento é mais aderente aos ciclos de liquidez internacional em relação à FBKF nas economias desenvolvidas.

\subsection{O Modelo de Investimento: Proposta Teórica}

O modelo de investimento a ser desenvolvido e estimado está associado à abordagem minskyana de instabilidade financeira e tem como ponto de partida a relação de causalidade entre o investimento e o nível de produto e emprego. Essa relação está expressa na equação 1 .

$$
\mathrm{Yt}=\alpha_{1} \mathrm{I} \mu_{\mathrm{t}}
$$

Em que $\alpha_{1}$ é o coeficiente da equação, $Y_{t}$ é o produto real no período $t$ e $I \mu$ é a média da taxa de investimento observada no período corrente e em períodos anteriores. Espera-se que $\alpha_{1}>0$. Para Keynes $(1999,1983)$, na economia monetária de produção o investimento é determinante do produto e emprego, ou seja, apenas a decisão de investir é analiticamente importante:

$4 \quad$ Ver, por exemplo, Thirwall (1979) e McCombie e Thirwall (1994). 
A teoria pode ser resumida pela afirmação de que, dada a psicologia do público, o nível de produção e do emprego como um todo depende do montante de investimento. Eu a proponho desta maneira, não porque este seja o único fator de que depende a produção agregada, mas porque, num sistema complexo, é habitual considerar como causa causans o fator mais sujeito a repentinas e amplas flutuações (KEYNES, 1999, p. 178).

A teoria a qual o autor se refere seria sua teoria do emprego, que tem seu ponto de partida no princípio da demanda efetiva, segundo o qual a decisão de investir é mais complexa e mais instável que a decisão de consumir. ${ }^{5}$ Enquanto o consumo é estável em relação à renda, o investimento depende da relação entre a eficiência marginal do capital ${ }^{6}$ e a taxa de juros, e ambas, por sua vez, têm por base precárias previsões do futuro. Por isso, o volume de investimento está sujeito a amplas flutuações, tornando-se a variável dinâmica do modelo de determinação do produto. Uma vez estabelecido o caráter determinante do investimento em relação ao nível do produto, faz-se necessário analisar os determinantes do investimento.

De acordo com a literatura evolucionária, o crescimento econômico de longo prazo depende, principalmente, do progresso tecnológico (FARGEBERG, 1994). Este, por sua vez, será tanto maior quanto maior for o grau de desenvolvimento do SI de um país. ${ }^{7}$ Esse argumento é compatível com a abordagem pós-keynesiana. O progresso tecnológico estimula o crescimento econômico e, simultaneamente, proporciona ganhos de produtividade e de competitividade para a economia (FREEMAN, 1995). Esse cenário reduz a incerteza e estimula o otimismo dos agentes, mitigando sua preferência pela liquidez e estimulando o animal spirits dos empresários. No âmbito do modelo de escolha de ativos de Keynes, o desenvolvimento do SI irá estimular, então, a taxa própria de juros dos ativos reais (ilíquidos) em detrimento da taxa própria de juros de ativos líquidos (como a moeda, por exemplo), aumentando a alocação da riqueza dos agentes em ativos reais, isto é, estimulando o investimento. Portanto, o grau de desenvolvimento do SI de uma economia deve ser contemplado na função investimento.

Por fim, argumentamos que os ciclos do sistema financeiro internacional e o grau de vulnerabilidade externa da economia também afetam o investimento.

$5 \quad$ Sobre o princípio da demanda efetiva, ver Davidson (1999) e Keynes (1983).

6 Sobre a eficiência marginal do capital, ver Keynes (1983).

7 Sobre o SI, Albuquerque (1996, p. 228, grifo nosso) comenta: "Trata-se de uma construção institucional que impulsiona o progresso tecnológico [...] através da construção de um sistema nacional de inovações, viabiliza-se a realização de fluxos de informação e conhecimento científico e tecnológico necessários ao processo de inovação. Esses arranjos institucionais envolvem firmas, redes de interação entre empresas, agências governamentais, universidades, institutos de pesquisa e laboratório de empresas, bem como a atividade de cientistas e engenheiros: arranjos institucionais que se articulam com o sistema educacional, com o setor industrial e empresarial e com as instituições financeiras, compondo o circuito dos agentes que são responsáveis pela geração, implementação e difusão das inovações tecnológicas". 
As economias podem ser classificadas segundo a categorização desenvolvida por Minsky (1986) para as posturas financeiras das unidades econômicas. Segundo Resende (2005) e Amado, Resende e Jaime Júnior (2007), economias com baixa vulnerabilidade externa são classificadas pelo sistema financeiro internacional como unidades hedge e economias com elevada vulnerabilidade externa seriam unidades especulativas ou ponzi. Assim, nos períodos de queda cíclica dos mercados financeiros mundiais, o racionamento de crédito (ou da saída líquida de capital) daí decorrente é mais intenso para as economias especulativas e ponzi, provocando efeitos assimétricos sobre os ciclos de crescimento das economias hedge, de um lado, e especulativas e ponzi, de outro. ${ }^{8}$ Portanto, uma variável que reflita os efeitos dos ciclos do sistema financeiro mundial sobre o investimento deve ser considerada na equação do investimento. Tal variável é a liquidez internacional, pois suas oscilações são uma proxy para os ciclos do sistema financeiro internacional (RESENDE; AMADO, 2007).

Contudo, a vulnerabilidade externa de uma economia pode ser amenizada pela política econômica, em particular pela política cambial. Conforme Paula e Alves Júnior (1999, p. 78),

[...] pode-se definir [...] fragilidade financeira externa como o grau de vulnerabilidade de uma economia às mudanças nas condições de financiamento oriundas de alterações nas taxas de juros externas ou ainda nas taxas de câmbio. A fragilidade pode se manifestar em nível operacional, o que [...] implicaria déficits na balança comercial [...] a resultante macroeconômica de posturas financeiras - em moeda estrangeira - dos agentes será uma economia frágil se o conjunto de agentes residentes, envolvidos em transações com o exterior, é de tal ordem que os compromissos a vencer [...] não possam ser cumpridos com o uso dos recursos externos disponíveis, a não ser que sejam complementados por refinanciamento das obrigações de curto prazo [...] daí deriva a importância de se calcular o grau de fragilidade externa de um país: uma avaliação da dependência de refinanciamentos para que se possa sustentar o "equilíbrio" do balanço de pagamentos e uma determinada política cambial.

A fragilidade financeira externa (FFE), definida em Paula e Alves Júnior (1999), se refere à capacidade de um país de honrar seus compromissos financeiros

8 Durante as fases de ascensão cíclica do sistema financeiro internacional, o problema da escassez de divisas externas nas economias com elevada vulnerabilidade externa é solucionado, o que enseja o aumento da oferta de finance (DOW, 1987, 1986) concomitantemente à redução da incerteza quanto ao crescimento econômico e à disponibilidade futura de divisas requeridas para a solvência do balanço de pagamentos. Esses fatores melhoram as expectativas dos agentes, provocando quedas na preferência pela liquidez e nas taxas de juros domésticas e aumentos na rentabilidade esperada dos ativos de capital. Desse modo, os investimentos são estimulados. $\mathrm{Na}$ queda cíclica do sistema financeiro internacional, o problema da escassez de divisas externas nas citadas economias é reposto e o investimento fica inibido (RESENDE, 2005). 
em moeda estrangeira. Esses autores elaboram um índice de FFE cujo cálculo é dado por:

$$
\mathrm{FFE}=\left(\mathrm{M}+\mathrm{D}_{\mathrm{j}}+\mathrm{D}_{\mathrm{os}}+\mathrm{A}+\mathrm{CCP}_{-1}+\mathrm{PLA}_{-1}\right) /\left(\mathrm{X}+\mathrm{R}_{\mathrm{j}}+\mathrm{R}_{\mathrm{os}}+\mathrm{RE}_{-1}+\mathrm{I}_{\mathrm{d}}+\mathrm{E}_{\mathrm{ml}}\right)
$$

Em que: $M=$ importações; $X=$ exportações; $D=$ despesas com juros $j$ e outros serviços (OS); $R=$ receitas com juros j e outros serviços (OS); $A=$ amortizações de empréstimos; $C C P_{-1}=$ estoque de capitais de curto prazo, defasado em um período; $P L A_{-1}=$ estoque de investimento líquido em portfólio, defasado em um período; $R E_{-1}=$ reservas internacionais acumuladas até o período anterior; $I_{d}=$ entradas de divisas correspondentes aos investimentos diretos; e $E_{m l}=$ empréstimos de médio e longo prazos.

Portanto, o índice de FFE serve como proxy para o grau de vulnerabilidade externa da economia e é relevante para indicar o comportamento do sistema financeiro internacional ao longo das fases de seus ciclos no que se refere ao grau de racionamento dos fluxos de capital para determinada economia. ${ }^{9}$ Portanto, uma variável que reflita o grau de vulnerabilidade externa da economia também deve ser contemplada na equação de investimento. Usaremos como proxy para tal o índice de FFE.

Desse modo, tanto os ciclos do sistema financeiro internacional, quanto também o grau de desenvolvimento relativo do SI de uma economia e o grau de sua FFE são relevantes para explicar o investimento agregado. Assim, a função investimento deve contemplar como variáveis explicativas a LI, a FFE e o SI, entre outras. A equação de investimento assume, então, a seguinte forma:

$$
I_{t}=f\left(L_{t}, F F E_{t}, S I_{t}, Z_{t}\right)
$$

Em que: $t=$ ano corrente; $I=$ investimento; $L I=$ liquidez internacional; $F F E=$ fragilidade financeira externa; $S I=$ grau de desenvolvimento relativo do sistema nacional de inovações da economia; e $Z_{t}=$ vetor formado pelas demais variáveis que afetam o investimento, presentes nas equações de investimento estimadas na literatura. Espera-se que LI e SI sejam positivamente correlacionados com I, enquanto a FFE deve ser negativamente correlacionada com $I$.

Embora o índice de FFE seja composto por uma série de outros componentes, além das importações e das exportações, tal variável pode ser modelada em função do saldo da balança comercial. Ao analisar cada um dos componentes do índice de FFE, constata-se que a FFE só aumenta (diminui) quando o passi-

9 Quanto mais elevado (menor) for o valor do índice da FFE, menor (maior) é a capacidade de um país cumprir seus compromissos financeiros mais imediatos, (não) sendo necessário recorrer ao refinanciamento externo ou aos seus estoques de reservas. 
vo externo líquido da economia eleva-se (diminui) e, por definição, as variações do passivo externo líquido correspondem aos saldos em transações correntes do balanço de pagamentos (SIMONSEN; CYSNE 1995). Portanto, a FFE só aumenta (diminui) quando há deterioração (melhora) do saldo em conta corrente. Têm-se como exceção duas situações: a) quando o aumento de capitais de curto prazo do período anterior é usado para pagar amortizações também do período anterior. Nesse caso, o passivo externo líquido não muda, mas a FFE do período corrente eleva-se. Tal aumento da FFE reflete uma mudança no perfil do passivo externo: amortizou-se parcela dos empréstimos e financiamentos de médio e longo prazo e ampliou-se na mesma medida o passivo externo de curto prazo (aumento do estoque de capitais de curto prazo); b) quando há aumentos em $I_{d}$ e $E_{m l}$ que não se destinam ao financiamento da conta corrente, mas, sim, ao acúmulo das reservas externas. $^{10}$

Se de um lado a FFE só aumenta (diminui), em geral, quando há déficits (superávits) em transações correntes, de outro lado os saldos em transações correntes são ditados, em grande medida, pelos saldos da balança comercial. Em geral as principais rubricas da balança de transações correntes das economias são exportações, importações, lucros e dividendos e juros, sendo que pagamentos ou recebimentos de juros no presente estão, muitas vezes, relacionados aos saldos comerciais passados. Esse argumento é corroborado pelo coeficiente de correlação entre os saldos da balança comercial e em transações correntes das economias em estudo. ${ }^{11} \mathrm{O}$ coeficiente de correlação entre os saldos para o período 1970-2006 é de 0,82 , o que sugere uma elevada correlação entre as contas supracitadas. Portanto, sendo os saldos comerciais passados e atual decisivos para a determinação do saldo em transações correntes no presente, e sendo este último, a saber, saldo em transações correntes, determinante da variação da FFE, esta pode ser modelada como função do saldo comercial. Nesse caso, o coeficiente de correlação estimado entre o índice de FFE e o saldo comercial da amostra de países desenvolvidos e em desenvolvimento, entre 1970-2006, é -0,60. ${ }^{12}$ Esse resultado sugere uma relação inversa e significativa entre essas variáveis.

10 No que se refere à fórmula de cálculo da $\mathrm{FFE}$, as variáveis $M, D_{\mathrm{j}}, D_{o s}, X, R_{\mathrm{j}}$ e $R_{o \mathrm{~s}}$ estão diretamente ligadas aos saldos em conta corrente. Com relação às demais variáveis que compõem a FFE, oscilações suas que produzem mudanças na FFE estão, em geral, associadas às alterações no saldo em conta corrente. Um aumento de $P L A_{-1}$ ou de $C C P_{-1}$, por exemplo, se não se destinar ao financiamento de um déficit em transações correntes, resultará em ampliação de $R E_{-1}$, deixando inalterados a FFE e o passivo externo líquido da economia.

11 Os dados para a construção das séries, saldo da balança comercial e saldo em transações correntes do balanço de pagamentos, no período entre 1970 e 2006, foram extraídos do banco de dados do World Bank (2006) para uma amostra composta de 23 países. Os 23 países são: Alemanha, França, Itália, Japão, Canadá, Estados Unidos, Reino Unido, Brasil, Argentina, Bolívia, Colômbia, Chile, Equador, México, Peru, Uruguai, Venezuela, Malásia, Tailândia, India, Indonésia, Filipinas e África do Sul.

12 Os dados que compõem o índice de FFE foram extraídos do banco de dados do World Bank (2006) uma para amostra de países supracitada no período 1970-2006. Entretanto, em razão da 
Portanto, o aumento do índice de FFE está associado à ampliação do déficit da balança comercial e à elevação do passivo externo líquido de uma economia. Desse modo, para tornar o modelo operacional, far-se-á uma simplificação: a FFE depende do saldo comercial corrente. Assim, tem-se:

$$
\mathrm{FFE}_{\mathrm{t}}=\mathrm{f}\left(\mathrm{X}_{\mathrm{t}} ; \mathrm{M}_{\mathrm{t}}\right)
$$

As exportações $(X)$ devem se correlacionar negativamente com a FFE e as importações $(M)$ devem se correlacionar positivamente. Conforme diversos estudos sobre o comportamento das exportações, as variáveis explicativas contempladas na equação de exportação consistem num indicador do nível de atividade doméstica, na taxa de câmbio real e no nível de renda mundial (CASTRO; CAVALCANTI, 1997). ${ }^{13}$ A equação 5 tem como base a literatura sobre equações de demanda e de oferta de exportação.

$$
X_{t}=f\left(Y_{t} ; C_{t} ; Y_{t}^{*}\right)
$$

Em que $X=$ quantum exportado; $Y=$ produto real doméstico; $C R=$ taxa de câmbio real; $Y^{*}=$ renda mundial real. Espera-se que as variáveis $C R$ e $Y^{*}$ sejam positivamente correlacionadas com $X$. O sinal da correlação entre $Y$ e $X$ é ambíguo, conforme a literatura sobre equações de exportação.

Como proxy para $Y^{*}$ utiliza-se o valor real da liquidez internacional (LI real), pois as variações da renda mundial estão associadas às oscilações da LI real (RESENDE; AMADO, 2007). Esse argumento é corroborado pelo coeficiente de correlação entre o índice de LI real em primeira diferença e o PIB mundial real em primeira diferença. ${ }^{14} \mathrm{O}$ coeficiente estimado apresentou o valor de 0,45 para o período 1970-2006, sugerindo uma correlação positiva entre as variáveis supracitadas. ${ }^{15} \mathrm{~A}$ série de LI foi elaborada a partir das seguintes rubricas do balanço de pagamentos dos países do G7: investimento de portfólio, derivativos financeiros

dificuldade de se obter todas as informações que constituem o índice de FFE nos balanços de pagamentos desses países, o cálculo desse indicador, possível de ser realizado neste trabalho, seguiu a seguinte fórmula: $\mathrm{FFE}=\left(\mathrm{M}+\mathrm{OIL}+\mathrm{PLA}_{-1}\right) /\left(\mathrm{X}+\mathrm{RE}_{-1}+\mathrm{I}_{\mathrm{d}}\right)$, em que $\mathrm{OIL}=$ outros investimentos líquidos, que representa o somatório de amortização de empréstimos (A) e estoque de capital de curto prazo (CCP). Essa mudança, no entanto, não desqualifica o indicador original de FFE a partir dos argumentos tratados, os quais são corroborados pelos resultados dos coeficientes de correlação.

13 Além disso, é comum, nessa abordagem, o uso da variável grau de ocupação da capacidade instalada como argumento na equação 5. Todavia, diversos estudos empíricos retiram essa variável da equação.

14 Para a série do PIB mundial utilizou-se o GDP mundial a preços constantes para o período 19702006. A fonte dos dados é World Bank (2006).

15 O coeficiente de correlação estimado entre o índice de liquidez internacional e o PIB mundial apresentou o valor de 0,94 para o período 1970-2006, porém a correlação em nível pode representar uma correlação espúria. 
e outros investimentos, conforme sugerido em Resende e Amado (2007). Para o cômputo da LI, foram somados os dados em módulo dos ativos e passivos dessas rubricas. A variável LI real é calculada pela média aritmética de dois períodos, passado e presente, conforme destacado pelos autores citados, e deflacionada pelo índice de preços ao produtor dos Estados Unidos. Os dados para a construção dessa série foram extraídos do banco de dados do FMI (IFS) para o período 1970-2006.

Visto que LI é proxy de $Y^{*}$, podemos substituir na equação $5 Y^{*}$ por LI. Substituindo a equação 1 na equação 5, obtém-se:

$$
X_{t}=f\left(I \mu_{t} ; C R_{t} ; L I\right)
$$

No que se referem às importações, estas são modeladas na literatura como função do nível do PIB, da taxa de câmbio real e do grau de utilização da capacidade instalada (U). Há estimações da equação de importações que substituem o U pelo PIB potencial (CASTRO; CAVALCANTI, 1997). Assim, tem-se:

$$
\mathrm{M}_{\mathrm{t}}=\mathrm{f}\left(\mathrm{Y}_{\mathrm{t}} ; \mathrm{CR}_{\mathrm{t}} ; \mathrm{Ut}\right)
$$

Em que $M=$ quantum importado e $U$ = grau de utilização da capacidade instalada. Substituindo a equação 1 na 7, obtém-se:

$$
\mathrm{M}_{\mathrm{t}}=\mathrm{f}\left(\mathrm{I} \mu_{\mathrm{t}} ; \mathrm{CR} ; \mathrm{Ut}\right)
$$

Substituindo as equações 6 e 8 na 4 , tem-se:

$$
\mathrm{FFE}=\mathrm{f}\left[\left(\mathrm{I}_{\mathrm{t}} ; \mathrm{CR} \mathrm{R}_{\mathrm{t}} \mathrm{LI}\right) ;\left(\mathrm{I} \mu_{\mathrm{t}} ; \mathrm{CR} ; \mathrm{Ut}\right)\right]
$$

Rearranjando os termos,

$$
\mathrm{FFE}=\mathrm{f}\left(\mathrm{I}_{\mathrm{t}} ; \mathrm{CR} \mathrm{R}_{\mathrm{t}} ; \mathrm{LI} ; \mathrm{Ut}\right)
$$

Substituindo a equação 10 na 3, tem-se:

$$
\mathrm{I}_{\mathrm{t}}=\mathrm{f}\left[\left(\mathrm{LI}_{\mathrm{t}}\right) ;\left(\mathrm{I}_{\mathrm{t}} ; \mathrm{CR}_{\mathrm{t}} ; \mathrm{LI}_{\mathrm{t}} ; \mathrm{Ut}\right) ;\left(\mathrm{SI}_{\mathrm{t}}\right) ;(\mathrm{Z} \mathrm{t})\right]
$$

Rearranjando os termos, obtém-se:

$$
I_{t}=f\left(L I_{t} ; \mu_{t} ; C R_{t} ; U t ; S I_{t} ; Z\right)
$$


A equação 12 contempla como argumentos do investimento a liquidez internacional $(L I)$, a média dos investimentos passados e atual $(I \mu)$, a taxa de câmbio real $(C R)$, o grau de utilização da capacidade instalada $(U),{ }^{16}$ o grau de desenvolvimento relativo do sistema nacional de inovações $(S I)$ e o vetor formado pelas variáveis explicativas utilizadas nos modelos de investimento presentes na literatura que trata desse tema $(Z)$.

A partir da estimação da equação de investimento (equação 12), é possível avaliar diretamente a influência da liquidez internacional sobre o investimento. A equação 1, ao captar como o investimento proporciona variações no produto da economia, pode ser relacionada com a equação 12 para mostrar os efeitos da liquidez internacional sobre o crescimento econômico. Além disso, é possível investigar se os efeitos da liquidez internacional sobre o investimento e o crescimento são distintos quando se considera o grupo das economias desenvolvidas e em desenvolvimento.

\section{Modelo de Investimento: Investigação Empírica}

A equação de investimento (equação 12) será estimada para um conjunto de países para o período para o qual há dados disponíveis: 1970-2006. Os países dividem-se em desenvolvidos (grupo dos G7) e em desenvolvimento (Brasil, Argentina, Bolívia, Colômbia, Chile, Equador, México, Peru, Uruguai, Venezuela, Malásia, Tailândia, Índia, Indonésia, Filipinas e África do Sul). A equação 12 foi expandida para equação 13 ao se explicitar as variáveis contidas em $Z$, tomando a seguinte forma:

$\mathrm{FBKF}_{\text {it }}=\alpha_{0}+\alpha_{1} \mathrm{LI}_{\mathrm{it}}+\alpha_{2} \mathrm{INV}_{\mathrm{it}}+\alpha_{3} \mathrm{CR}_{\mathrm{it}}+\alpha_{4} \mathrm{VGDP}_{\mathrm{it}}+\alpha_{5} \mathrm{SI}_{\mathrm{it}}+\alpha_{6} \mathrm{CRED}_{\mathrm{it}}+$ $\alpha_{7} \operatorname{TRJ}_{\mathrm{it}}+\alpha_{8} \mathrm{D}_{\mathrm{it}}+\alpha_{9} \mathrm{DLI}_{\mathrm{it}}+\alpha_{10} \mathrm{DCRED}_{\mathrm{it}}+\alpha_{11} \mathrm{DSI}_{\mathrm{it}} \alpha_{12} \mathrm{DYEAR}_{\mathrm{it}}+\varepsilon_{\mathrm{it}}$

Em que:

$F B K F_{\text {it }}$ em substituição a $I_{\text {it }}=$ investimento agregado = formação bruta de capital fixo, a preços constantes de 2000 (WORLD BANK, 2006); ${ }^{17}$

16 A variável acelerador do investimento é representada pelo grau de utilização da capacidade instalada ou pela primeira diferença do PIB: $\ln \left(\mathrm{GDP}_{\mathrm{it}}\right)-\ln \left(\mathrm{GDP}_{\mathrm{it}-1}\right)$, em que GDP é o PIB (GDP) do país $i$ no período $t$.

17 A taxa de investimento, FBKF/PIB, não foi usada como variável dependente porque o modelo inicial de investimento que incluiu essa variável não produziu o melhor ajustamento dos dados, o que sugeriu a substituição dessa variável pela FBKF na formulação do modelo final. Ademais, a maioria dos trabalhos empíricos acerca dos determinantes do investimento utiliza dados anuais sobre a FBKF privada da economia ao invés de usar a taxa de investimento. Há, porém, exceções, tais como Galbis (1979), Greene e Villanueva (1991) e Muinhos e Alves (2003 apud ALVES; LUPORINI, 2007), que utilizam a taxa de investimento como variável endógena em seus estudos. 
$I N V_{i t}$ em substituição a $I \mu_{i t}=$ taxa média de investimento = média aritmética entre a taxa de investimento no período $t$ e em $t_{-1}$, a preços constantes de $2000 ; 18$

$V G D P_{i t}=$ acelerador do investimento $=\ln \left(G D P_{i t}\right)-\ln \left(G D P_{i t-1}\right)$, em que GDP é o PIB (GDP) no país $i$, a preços de 2000 ; $l n=$ logaritmo; ${ }^{19}$

$S I_{i t}=$ grau de desenvolvimento relativo do sistema nacional de inovação = medida do progresso tecnológico de um país em relação ao resto do mundo; $\mathrm{SI}_{\mathrm{it}}=1 / 2\left(\log _{10} \mathrm{Art}_{\mathrm{it}}+\log _{10} \mathrm{Pat}_{\mathrm{it}}\right)$, em que Art $_{\mathrm{it}}$ representa a participação do país i na produção mundial per capita de artigos científicos, no período 1970-2006, e Patit é a participação do país i na produção mundial per capita de patentes concedidas pelo United States Patent and Trademark Office, no período 1970-2006. ${ }^{20}$ Essa medida do progresso tecnológico é recorrente na literatura evolucionária, segundo Bernardes e Albuquerque (2003, p. 873);

$L I_{i t}=$ liquidez internacional real, a preços de 2000;

$C R E D_{i t}=$ crédito doméstico, a preços de 2000 , representado pela série net domestic credit (em moeda corrente), deflacionados pelo índice de preços ao consumidor, ano base $=2000$ (WORLD BANK, 2006);

$C R_{\text {it }}=$ taxa de câmbio real; ${ }^{21}$

$T R J_{i t}=$ taxa de juros real; ${ }^{22}$

18 Os dados referem-se às séries de formação bruta de capital fixo, a preços constantes de 2000, como proporção do PIB, a preços constantes de 2000, fornecidas pelo World Bank (2006).

19 Para a série do PIB utilizou-se o GDP a preços constantes disponíveis no banco de dados do World Bank (2006). Inicialmente, estimou-se a equação 13 com a variável acelerador do investimento representada por U, grau de utilização da capacidade instalada, e testou-se sua significância. Porém, a variável acelerador do investimento, representada pela primeira diferença do PIB, produziu o melhor ajustamento dos dados. O cálculo do grau de utilização da capacidade instalada foi baseado nas séries do GDP potencial calculado pelo filtro de Hodrick-Prescott.

20 Para a série de artigos científicos utilizaram-se dados do Institute of Scientific Information, e para a série de patentes utilizaram-se dados do United States Patent and Trade Office. Os dados referentes à população são fornecidos pelo World Bank. Bolívia, Chile, Colômbia, Equador, Indonésia, Malásia, Peru, Uruguai e Venezuela não apresentam dados para toda a série de Art e de Pat. Quando as informações estavam ausentes optou-se por calcular os dados através de transformações lineares das informações existentes.

21 O Banco Mundial (2006) disponibiliza a série da taxa de câmbio real efetiva. Contudo, esses dados não estão disponíveis para todos os países da amostra. Desse modo, utilizou-se para cálculo da taxa de câmbio real a seguinte equação: $e=E^{*} P^{*} / P$, em que $e$ é a taxa de câmbio real, $E$ é a taxa de câmbio nominal, $P^{*}$ é o índice de preços ao consumidor $(2000=100)$ dos Estados Unidos e $P$ é o índice de preços doméstico. Os dados dessas séries são disponibilizados pelo Banco Mundial (2006).

O dado do International Financial Statistics do FMI online utilizado para a variável taxa de juros foi o deposit interest rate (\%). Contudo, esse dado não está disponível para todos os países e todos os anos da amostra. Ademais, a taxa de juros real é representada por $\left.\left\{\left[(1+i) /\left(1+\eta_{t+1}\right)\right]-1\right]\right\} * 100$, em que $i_{t}$ é a taxa nominal de juros sobre os depósitos no período corrente (dividida por 100) e $\eta t+1$ é a taxa da inflação do período seguinte (dividida por 100). Como índice de preços utilizou-se o índice de preços ao consumidor ano base $=2000$. Para mais detalhes sobre a fórmula de cálculo da taxa de juros real, ver Greene e Villanueva (1991). 
$D_{i t}=$ variável dummy com valor igual a 1 para países desenvolvidos e 0 para países em desenvolvimento;

$D L I_{i t}=$ termo de interação entre países desenvolvidos e a variável de liquidez internacional real no país $i$. Esse termo permite estimar o diferencial do coeficiente da liquidez internacional real entre o grupo das economias desenvolvidas e o grupo das economias em desenvolvimento. O termo foi construído de acordo com Wooldridge (2006, p. 223-227), da seguinte forma: Dit"LIt, em que $D$ assume o valor 1 para países desenvolvidos e 0 para países em desenvolvimento e LI é a liquidez internacional real. Nesse sentido, a natureza do termo de interação DLI será zero para qualquer país em desenvolvimento da amostra e igual ao nível de liquidez internacional para qualquer país desenvolvido da amostra.

$D C R E D_{i t}=$ termo de interação entre países desenvolvidos e a variável crédito doméstico no país i.

$D S I_{i t}=$ termo de interação entre países desenvolvidos e a variável grau de desenvolvimento relativo do sistema nacional de inovação no país $i$.

$D Y E A R_{\text {it }}=$ conjunto completo de variáveis dummies anuais para o período 1970-2006. ${ }^{23}$

$\varepsilon_{i t}=$ componentes do erro (erros idiossincrático e específico). O índice it indica, respectivamente, os diferentes países e anos a serem considerados. Para a análise econométrica, todas as variáveis, com exceção da taxa de juros real, ${ }^{24}$ foram "log-linearizadas", utilizando-se o logaritmo natural e, quando apropriado, calculadas a preços constantes de 2000.

A amostra analisada presta-se a comparações do papel que as variáveis LI, CRED e SI exercem sobre o investimento nos países desenvolvidos vis-à-vis os países em desenvolvimento. Assumimos o argumento de Resende (2005) e Raposo (2009) de que as economias com baixo (alto) grau de vulnerabilidade externa e elevado (baixo) grau de desenvolvimento do SI são as economias desenvolvidas (em desenvolvimento). Assim, foram introduzidas variáveis dummy (D, DLI, DCRED, DSI) para investigar se há diferença no grau de estímulo dessas variáveis ou sobre o investimento entre esses dois grupos de países durante o período analisado.

Para os coeficientes $\alpha_{1}, \alpha_{2}, \alpha_{4}, \alpha_{5}$ e $\alpha_{6}$ espera-se um sinal positivo, e, para $\alpha_{7}$, um sinal negativo. Para o coeficiente $\alpha_{3}$, o sinal é ambíguo. Adicionando um

23 Foi incluído na equação um conjunto completo de dummies anuais para controlar as tendências dos países sobre o investimento, e sua significância conjunta foi testada. Obteve-se $\mathrm{p}$-valor $=0,99$ e, portanto, as dummies anuais são conjuntamente não significativas pelas estimações do modelo por mínimos quadrados ordinários (MQO) e por efeitos aleatórios.

24 A série de taxa de juros real utilizada apresenta-se incompleta para a maioria dos países da amostra. Ademais, em razão da transformação da série para valores reais, alguns dados tornam-se negativos, logo decidiu-se por não "log-linearizar" essa série. 
termo de interação entre países desenvolvidos e liquidez internacional no modelo de investimento, pode-se obter o diferencial estimado do coeficiente da liquidez internacional entre os dois grupos de países (desenvolvidos e em desenvolvimento). Semelhante procedimento será realizado para calcular o diferencial dos coeficientes de CRED e SI entre os dois grupos de países. ${ }^{25}$ Os países desenvolvidos são os do G7 e os países em desenvolvimento correspondem aos demais países da amostra.

$\mathrm{Na}$ economia monetária de produção, o finance antecede o investimento. Atribui-se como proxy ao finance a variável crédito bancário. Portanto, espera-se uma correlação positiva entre o volume de crédito bancário transferido ao setor privado e o investimento agregado.

Em conformidade com a análise realizada nos itens anteriores, espera-se que o coeficiente estimado da variável de liquidez internacional, $\alpha_{1}$, seja mais elevado para as economias em desenvolvimento em relação às desenvolvidas. Então, para os países em desenvolvimento $D=0$ na equação 13 , ver-se-á que o intercepto para esses países é $\alpha_{0}$, enquanto a inclinação na liquidez internacional (LI) é $\alpha_{1}$. Para os países desenvolvidos, usa-se $D=1$, assim o intercepto para esses países será $\alpha_{0}+\alpha_{8}$ e a inclinação da LI será $\alpha_{1}+\alpha_{9}$. Portanto, $\alpha_{8}$ mede a diferença nos interceptos entre países desenvolvidos e em desenvolvimento, enquanto $\alpha_{9}$ mede a diferença do estímulo da LI sobre a FBKF entre países desenvolvidos e em desenvolvimento. O mesmo procedimento foi adotado para as variáveis DCRED e DSI. Os coeficientes estimados de CRED e de SI dos países em desenvolvimento são dados, respectivamente, por $\alpha_{6}$ e $\alpha_{5}$, enquanto para o grupo dos países desenvolvidos os coeficientes estimados são $\alpha_{6}+\alpha_{10}$ e $\alpha_{5}+\alpha_{11}$, respectivamente.

Espera-se rejeitar a hipótese de que os estímulos da LI, do CRED e do SI sobre a FBKF sejam os mesmos para países desenvolvidos e em desenvolvimento. Em termos do modelo (equação 13), isso é declarado como $H_{0}: \alpha_{9}=0, H_{0}: \alpha_{10}=0$ $e H_{0}: \alpha_{11}=0$. Observa-se que essa hipótese não faz nenhuma restrição sobre a diferença nos interceptos, $\alpha_{0}$. Também é interessante testar a hipótese de que o efeito da LI sobre a FBKF seja idêntico entre os dois grupos de países. Isso significa que $\alpha_{8}$ e $\alpha_{9}$ devem ambos ser zero sob hipótese nula. Espera-se rejeitar essa hipótese. Na equação 13 será adotado um teste $F$ para testar $H_{0}: \alpha_{8}=0 ; \alpha_{9}=0$. Do mesmo modo, serão testadas as hipóteses de que os coeficientes estimados do CRED e do SI são mais elevados para as economias desenvolvidas em relação às em desenvolvimento. Para tanto, é necessário que os testes de $t$ e $F$ rejeitem suas respectivas hipóteses nulas.

25 Segundo Ai e Norton (2003), em modelos lineares, um teste t do coeficiente é suficiente para diagnosticar a significância estatística do efeito da variável de interação. Para mais detalhes, ver Ai e Norton (2003, p. 124). 


\subsection{Estimação do Modelo de Investimento e Resultados}

Visando testar a hipótese de que o investimento nas economias em desenvolvimento é mais aderente aos ciclos da liquidez internacional vis-à-vis o investimento nas economias desenvolvidas, foi realizada uma análise de painel não balanceado, com diferenças entre as observações de cada país e de cada período de tempo. ${ }^{26}$ Dado que o painel deste trabalho apresenta um número de observações de tempo maior que o de países, ${ }^{27}$ propõe-se a estimação do modelo de investimento pelo método panel corrected standard errors (PCSE), originalmente desenvolvido por Beck e Katz (1995). Esse método consiste numa correção dos erros anteriormente apontados, considerando o painel não balanceado e a possível existência de autocorrelação e de heteroscedasticidade. ${ }^{28}$

Antes de estimar o modelo, é necessário verificar se a natureza estatística das séries envolvidas implica estimativas não espúrias. O emprego de teste de raiz unitária em painel é recente (LEVIN; LIN; JAMES CHU, 2002; IM; PESARAN; SMITH, 2003; HADRI, 2000). Para dados em painel heterogêneo e desbalanceado, o procedimento mais adequado é aplicar os testes de raiz unitária para dados em painel desenvolvido por Im, Pesharam e Shin (BANERJEE, 1999). ${ }^{29}$

Conforme os resultados da Tabela 1, apenas para CRED e DCRED não se pode rejeitar a hipótese de não estacionariedade das séries em nível nos modelos estimados com constante e tendência. As demais séries são estacionárias, isto é, integradas de ordem zero, I(0).

26 A justificativa para a escolha de uma amostra não balanceada é que esta permite o uso de maior quantidade de informações sobre os países, visto que o banco de dados apresenta lacunas. A amostra não balanceada não exige o mesmo número de países para cada grupo e o mesmo número de dados para cada país. Já a amostra balanceada, por sua vez, exige o cumprimento desses critérios. Essas limitações determinaram a utilização de uma amostra não balanceada. Para mais detalhes sobre o tipo de amostra e método de estimação, ver Wooldridge (2002) e Baltagi (2001).

27 A amostra é de 23 países, a saber: Alemanha, França, Itália, Japão, Canadá, Estados Unidos, Reino Unido, Brasil, Argentina, Bolívia, Colômbia, Chile, Equador, México, Peru, Uruguai, Venezuela, Malásia, Tailândia, Índia, Indonésia, Filipinas e África do Sul.

28 A estimativa do painel dinâmico requer alguns cuidados. A estimação através da técnica de momentos (GMM) (em inglês, generalized method of moments), por exemplo, não é recomendada para uma amostra em painel de dimensões similares às deste trabalho. Isso porque, de acordo com Mátyás (1999), com um grande número de observações ao longo do tempo para um número comparativamente pequeno de países, os estimadores LSDV ou within são consistentes, mesmo que não completamente eficientes. Depois, como é mostrado em Arellano e Bond (1991), entre outros, a quantidade de condições de momentos disponíveis aumenta quadraticamente em $T$, o que torna o peso computacional do GMM, para um T elevado, demasiado oneroso. Nesse caso, os estimadores GMM, por serem relativamente exigentes e não darem provas de grande eficiência, são preteridos. Para mais detalhes, ver Mátyás (1999) e Baltagi (2001).

29 Para mais detalhes sobre o teste, ver Im, Pesaran e Smith (2003). 
Tabela 1 - Testes Im-Pesharam e Shin para raiz unitária em painel

\begin{tabular}{llll}
\hline Variável & $\begin{array}{l}\text { Ordem da de- } \\
\text { fasagem lags }\end{array}$ & Valor $\mathbf{t}$ & p-valor \\
\hline FBKF & 0 a 2 & -334.45 & 0.00 \\
INV & 1 a 7 & -281.79 & 0.00 \\
VGDP & 0 a 6 & -124.39 & 0.00 \\
SI & 0 a 1 & -794.27 & 0.00 \\
LI & 3 & -543.19 & 0.00 \\
DLI & 3 & -295.03 & 0.00 \\
CRED & 0 a 5 & 0.78 & 0.78 \\
CR & 0 a 4 & -112.67 & 0.00 \\
TRJ & 0 a 3 & -737.88 & 0.00 \\
DCRED & 0 a 4 & 0.90 & 0.84 \\
DSI & 0 a 3 & -472.45 & 0.00 \\
\hline
\end{tabular}

Fonte: Elaboração própria.

Nota: a) testes realizados adotando-se constante e tendência linear na equação de teste; b) lags representam o número de defasagens utilizadas nos testes, selecionado pelo critério SIC.

Para as variáveis CRED e DCRED, realizaram-se ainda os testes sobre a sua estacionariedade proposto por Maddala e Wu (1999), amplamente adotado na literatura de estatística e adequado para painéis não balanceados. ${ }^{30}$ Os valores de significância para os testes de raiz unitária foram aproximados por Mackinnon (1991). Os resultados obtidos estão na Tabela $2 .^{31}$

$30 \quad$ Para mais detalhes sobre o teste, ver Maddala e Wu (1999).

31 Não utilizamos esse procedimento para as outras séries porque para a obtenção de estatísticas do teste de Maddala e Wu (1999) foi utilizada a aproximação de Mackinnon (1991). Uma vez que essas distribuições não são exatas, optamos por utilizar esse teste somente para as variáveis que não se mostraram I(0) no teste anterior (Tabela 1 ). 
Tabela 2 - Testes de Maddala e Wu para raiz unitária em painel

\begin{tabular}{llcccc}
\hline Variável & $\begin{array}{l}\text { Elementos } \\
\text { deterministicos }\end{array}$ & \multicolumn{2}{c}{ Fisher-ADF } & \multicolumn{2}{c}{ Fisher-PP } \\
& Valor $\mathbf{t}$ & p-valor & Valor $\mathbf{~}$ & p-valor \\
\hline CRED & $\mathrm{C}$ & -334.45 & 0.56 & 684.83 & 0.01 \\
& $\mathrm{C} / \mathrm{T}$ & 582.73 & 0.10 & 629.67 & 0.04 \\
$\mathrm{D}(\mathrm{CRED})$ & $\mathrm{C}$ & 178.81 & 0.00 & 348.84 & 0.00 \\
& $\mathrm{C} / \mathrm{T}$ & 133.92 & 0.00 & 297.09 & 0.00 \\
$\mathrm{DCRED}$ & $\mathrm{C}$ & 181.62 & 0.19 & 240.72 & 0.04 \\
& $\mathrm{C} / \mathrm{T}$ & 145.05 & 0.41 & 867.91 & 0.85 \\
$\mathrm{D}(\mathrm{DCRED})$ & $\mathrm{C}$ & 780.73 & 0.00 & 778.24 & 0.00 \\
& $\mathrm{C} / \mathrm{T}$ & 614.05 & 0.00 & 691.16 & 0.00 \\
\hline
\end{tabular}

Fonte: Elaboração própria.

Nota: a) $\mathrm{D}=$ primeira diferença da variável; b) $\mathrm{C}=$ modelo com constante; $\mathrm{C} / \mathrm{T}=$ modelo com constante e tendência.

De acordo com a Tabela 2, quando se consideram ambos os testes adotados, Fisher-ADF e Fisher-PP, e também os casos com presença e ausência da tendência temporal, os resultados são ambíguos. Dessa forma, optou-se por utilizar todas as variáveis em nível, inclusive CRED e DCRED. O próximo passo foi estimar a equação seguinte para dados de painel pelo método PCSE:

$$
\begin{aligned}
& \mathrm{FBKF}_{\text {it }}=\alpha_{0}+\alpha_{1} \mathrm{INV}_{\text {it }}+\alpha_{2} \mathrm{VGDP}_{\mathrm{it}}+\alpha_{3} \mathrm{SI}_{\mathrm{it}}+\alpha_{4} \mathrm{LI}_{\mathrm{t}}+\alpha_{5} \mathrm{CRED}_{\mathrm{it}}+\alpha_{6} \mathrm{CR}_{\mathrm{it}-1}+\alpha_{7} \mathrm{TRJ}_{\mathrm{it}-1} \\
& +\alpha_{8} \mathrm{D}_{\mathrm{it}}+\alpha_{9} \mathrm{DLI}_{\mathrm{it}}+\alpha_{10} \mathrm{D} 5_{\mathrm{it}}+\alpha_{11} \mathrm{DCRED}_{\mathrm{it}}+\alpha_{11} \mathrm{DSI}_{\mathrm{it}}+\varepsilon_{\mathrm{it}}
\end{aligned}
$$

A equação 14 apresenta as seguintes alterações em relação à equação 13: inclusão da variável dummy para o ano de $1985^{32}$ e introdução de defasagem de um período nas séries de $\mathrm{CR}$ e TRJ. ${ }^{33} \mathrm{~A}$ Tabela 3 apresenta os resultados da estimação por PCSE do modelo de investimento. ${ }^{34}$ Os dados utilizados são anuais, abrangendo 23 países no período 1970-2006.

32 Incluiu-se na equação um conjunto completo de dummies anuais para controlar as tendências dos países sobre a FBKF, e sua significância conjunta foi testada. As dummies anuais são conjuntamente não significantes. Entretanto, a dummy para o ano de 1985 foi estatisticamente significativa e sua inclusão na equação alterou algumas elasticidades.

33 Diversos trabalhos, a exemplo de Melo e Rodrigues Júnior (1998) e Pelicioni e Resende (2009), adotam alguma defasagem nas variáveis do modelo de investimento em que o impacto contemporâneo das variáveis explicativas sobre a FBKF seja pequeno. Esse é o caso das taxas de cambio real e juros real. A primeira defasagem de CR é bastante significante e indica uma relação negativa entre CR e FBKF a partir de um ano (ver Tabela 3). Isso faz mais sentido do que ter um efeito contemporâneo no caso dessas variáveis.

34 Os coeficientes e o erro padrão são estimados no comando xtgee do programa Stata. Segundo Beck e Katz (1995), em painéis de dimensões similares aos deste trabalho, para controlar prováveis problemas de heteroscedasticidade e correlação de resíduos entre países, propõe-se 
As estimativas foram geradas pelos seguintes modelos: a) PCSE (MQO); b) PCSE robusto (MQO); c) PCSE WLS robusto; d) PCSE AR(1); e e) PCSE AR(2) EQ1, 2 e 3. As estimações por PCSE de $a, b$ e $c$ aparecem apenas como referência. Elas podem dar alguma ideia do ganho de eficiência em se estimar o modelo por dados em painel pelo método PCSE com a transformação de Prais-Winstem. Os modelos mais fidedignos são os que aparecem nas colunas d) PCSE AR(1) e e) PCSE AR(2) EQ1, 2 e 3. As variáveis DSI e DCRED só foram contempladas nas equações PCSE AR (2) EQ2 e EQ3, respectivamente, pois quando incluídas nas demais equações apresentaram resultados de baixa significância, o que sugeriu a eliminação dessas variáveis na formulação desses modelos iniciais. Testes $F$ de variáveis omitidas do modelo permitiram verificar que de fato sua exclusão do modelo não traria prejuízos a sua explicabilidade. ${ }^{35}$

Conforme a Tabela 3, os resultados obtidos para os modelos PCSE AR1 e PCSE AR2 (EQ1, 2 e 3) corroboram muitas hipóteses formuladas neste trabalho. Os sinais dos coeficientes obtidos para todas as variáveis explicativas correspondem aos sinais previstos pela teoria. Os resultados para os modelos PCSE AR1 e $\mathrm{AR2}$ EQ1 e EQ2 indicam que todas as variáveis propostas são estatisticamente significativas na explicação da FBKF, a pelo menos $5 \%$.

A FBKF revela uma forte resposta a variações do produto (coeficiente da $\operatorname{VGDP}=1,45)$. Esse resultado é compatível com a maioria dos trabalhos empíricos existentes sobre os determinantes do investimento no Brasil e em outros países e confirma a importância do efeito acelerador sobre o investimento.

Os resultados mostram que um aumento da média dos investimentos passado e presente (INV) gera um aumento do investimento corrente. Nas equações PCSE AR(1) e PCSE AR(2), o coeficiente estimado é de 1,31. Esse resultado confirma a importância da irreversibilidade do investimento e é compatível com a hipótese de cunho pós-keynesiano de que o aumento (queda) do investimento eleva o otimismo (pessimismo) dos agentes, estimulando (desestimulando) novas decisões de investimento.

Em relação à taxa de câmbio real, as equações PCSE AR indicam existência de relação negativa com a variável dependente, FBKF. Assim, uma taxa de câmbio

uma correção no cálculo do erro padrão, o PCSE. O comando xtgee do Stata permite estimar a equação mediante esse procedimento. Contudo, foram realizadas estimações das equações em estudo com o comando xtpcse com ponderação para correlação serial dos resíduos e heteroscedasticidade. No entanto, os resultados não foram reportados em virtude da maior robustez e eficiência apresentada pela estimação da equação com o comando xtgee.

Os resultados dos testes de $F$ para omissão das variáveis DSI e DCRED nos modelos de investimento, a saber, PCSE (MQO), PCSE robusto (MQO), PCSE WLS robusto e PCSE AR(1), foram os seguintes: omissão de DSI em PCSE (MQO): $\mathrm{F}=5,22$ [0,0224]; omissão de DCRED em PCSE (MQO): $F=0,12$ [0,7244]; omissão de DSI em PCSE robusto (MQO): $F=0,25$ [0,06196]; omissão de DCRED em PCSE robusto (MQO): $\mathrm{F}=0,01$ [0,9104]; omissão de DSI em PCSE WLS robusto: $\mathrm{F}=0,01$ [0,9151]; omissão de DCRED em PCSE WLS robusto: $\mathrm{F}=0,25$ [0,6184]; omissão de DSI em PCSE AR(1): F=0,09 [0,7648]; omissão de DCRED em PCSE AR(1): F=2,61 [0,1063]. 
mais desvalorizada desestimula a importação de bens de capital, com efeitos deletérios sobre a FBKF, pelo menos no curto prazo. Esse resultado é confirmado para o Brasil por Alves e Luporini (2008) e Ribeiro e Teixeira (2001).

A importância do sistema nacional de inovação sobre a FBKF é confirmada na estimação dos modelos PCSE AR. Os resultados mostram que o desenvolvimento relativo do SI estimula positivamente a FBKF. O coeficiente estimado é significativo ao nível de $1 \%$. Um incremento de $10 \%$ no SI gera impacto positivo de cerca de $0,21 \%$ na FBKF.

A elevação da taxa de juros real tem impacto negativo sobre a FBKF. Porém, o valor absoluto do coeficiente estimado $(0,0002)$ foi muito pequeno, o que indica que, no período 1970-2006, variações nos níveis da taxa de juros não impactaram de forma efetiva o investimento. Essa evidencia também foi encontrada nos trabalhos de Pelicioni e Resende (2009) e Alves e Luporini (2007). A dificuldade de se encontrar coeficientes negativos e significativos para essa variável é reportada na literatura, inclusive na internacional (CHIRINKO, 1993). Uma explicação possível para isso pode estar relacionada à baixa disponibilidade de recursos financeiros disponíveis para o financiamento do investimento para países em desenvolvimento. As restrições de crédito nesses países podem afetar o investimento de forma direta. Nesse caso, a taxa de juros torna-se secundária na determinação do investimento se as firmas não tiverem acesso aos recursos necessários para a implementação do investimento.

A importância do crédito (finance) para o investimento é confirmada pelos modelos PCSE AR. Os coeficientes estimados do CRED e da LI mostram que a expansão da FBKF depende, entre outros fatores, do crédito doméstico e externo, confirmando o resultado esperado pela abordagem pós-keynesiana. O coeficiente estimado do CRED é 0,072 e o da LI é 0,15. ${ }^{36}$

Por fim, destaca-se a confirmação empírica da necessidade de diferenciar na análise o grupo de países desenvolvidos e o de países em desenvolvimento. Aquele grupo apresenta um nível de investimento superior ao obtido para o grupo de países em desenvolvimento. O coeficiente estimado de $D$ foi positivo e significativo ao nível de 1\% para todos os modelos, exceto para PCSE AR2 EQ3.

Ademais, os resultados dos coeficientes estimados para LI e DLI confirmam a hipótese pós-keynesiana de que o coeficiente estimado da variável de liquidez internacional é mais elevado para as economias em desenvolvimento em relação às desenvolvidas. A elasticidade estimada da FBKF em relação à liquidez internacional dos países em desenvolvimento (modelos PCSE AR) é de 0,15\%. Um incre-

36 O resultado obtido é compatível com os estudos de Sundararajan e Thakur (1980), Blejer e Khan (1984), Garcia (1987), Left e Sato (1988), Studart (1992), Jacinto e Ribeiro (1998) e Ribeiro e Teixeira (2001 apud ALVES; LUPORINI, 2007), que incluem variáveis financeiras nos estudos empíricos e indicam que a disponibilidade de crédito é uma das variáveis relevantes para o investimento privado nos países em desenvolvimento. 
mento de $10 \%$ no volume de liquidez internacional gera impacto positivo de cerca de 1,5\% na FBKF desses países. Para países desenvolvidos, tal elasticidade é de $0,15-0,066=0,085 \%$ (PCSE AR1 e PCSE AR2 EQ1), ou seja, um incremento de $10 \%$ na liquidez internacional afeta a FBKF desses países em $0.85 \%$. A diferença de 0.065\% é estatisticamente significante. Para as equações PCSE AR2 EQ2 e EQ3, tal diferença é ainda maior. Dessa forma, corrobora-se a tese de que o efeito da liquidez internacional sobre o investimento não é o mesmo para países desenvolvidos e em desenvolvimento, sendo maior para os últimos.

A estatística $F$ de Ho: $\alpha_{D}=0 ; \alpha_{D L I}=0$ é $F=34,75$ e o p-valor é zero. Logo, ao rejeitarmos a hipótese nula, concluímos que as oscilações da LI são mais relevantes para explicar a FBKF nos países em desenvolvimento do que nos países desenvolvidos. Corrobora-se, então, a hipótese de que os ciclos das economias em desenvolvimento são mais aderentes aos ciclos da liquidez internacional do que os ciclos das economias desenvolvidas. Essa hipótese já havia sido apresentada em outros autores, tais como Amado (2003) e Resende (2005), sem, contudo, haver comprovação empírica. Argumentou-se que o baixo desenvolvimento relativo do SI das economias em desenvolvimento produz efeitos deletérios sobre sua competitividade, elevando sua vulnerabilidade externa. O pequeno desenvolvimento relativo do SI associa-se, também, a deficiências do sistema financeiro doméstico. Portanto, as economias em desenvolvimento sofrem não apenas de recorrência de escassez de divisas externas e de restrição de balanço de pagamentos ao seu crescimento, como também de ausência de mecanismos adequados de finance e de funding para o investimento e para a sustentação de seu crescimento. Entretanto, nos períodos de aumento cíclico da liquidez mundial, a restrição de divisa externas é aliviada, a oferta de finance eleva-se e a incerteza dos agentes quanto à escassez de divisas externas e ao crescimento econômico é mitigada. Sendo assim, a preferência pela liquidez se retrai e a eficiência marginal do capital eleva-se, estimulando o investimento nessas economias. O oposto se verifica nas fases descendentes do ciclo da liquidez internacional. Esse mesmo processo também ocorre para as economias desenvolvidas, porém com menor intensidade.

Nos modelos PCSE AR2 EQ2 e EQ3 foram incluídas, respectivamente, as interações DSI e DCRED. Essas variáveis são conjuntamente significativas ao nível de $1 \%$, com estatística de $\mathrm{F}=43,37$, para a PCSE AR2 EQ2, e $\mathrm{F}=38,78$ para a equação PCSE AR2 EQ3.

O coeficiente estimado de SI dos países em desenvolvimento é de 0,021. Para países desenvolvidos, o coeficiente estimado, dado pela soma das elasticidades de $\mathrm{SI}$ e de DSI na EQ2, é de 0,021 +0,018 =0,039. A diferença de 0,018 indica que em países cujo SI é mais desenvolvido, a exemplo das economias desenvolvidas, o efeito das oscilações do SI sobre a FBKF é superior comparado ao caso dos países 
em desenvolvimento, cujo SI é menos desenvolvido. Entretanto, essa diferença não é grande e nem é estaticamente significativa.

O coeficiente estimado do CRED dos países desenvolvidos, dado pela soma entre as elasticidades de CRED e DCRED na EQ $3(0,061+0,125=0,186)$, é superior ao coeficiente de CRED dos países em desenvolvimento $(0,061)$ e estatisticamente significativo, embora este último (coeficiente de CRED) não apresente significância estatística. Esse resultado confirma a importância da disponibilidade de crédito para a FBKF, especialmente para países desenvolvidos, bem como confirma a existência de racionamento de crédito e de um mercado de capitais pouco desenvolvidos no caso dos países em desenvolvimento.

Ademais, a estatística $F$ de $H 0: \alpha_{D}=0 ; \alpha_{D S I}=0$ é $F=26,09$ para a PCSE AR2 EQ2, e a $F$ de $H 0: \alpha_{D}=0 ; \alpha_{D C R E D}=0$ é $F=27,95$ para a PCSE AR2 EQ3. Então, ao rejeitarmos a hipótese nula, também se conclui pelo modelo que considera um diferencial dos efeitos sobre a FBKF entre os países desenvolvidos e em desenvolvimento no tocante ao grau de desenvolvimento relativo do SI e CRED. 


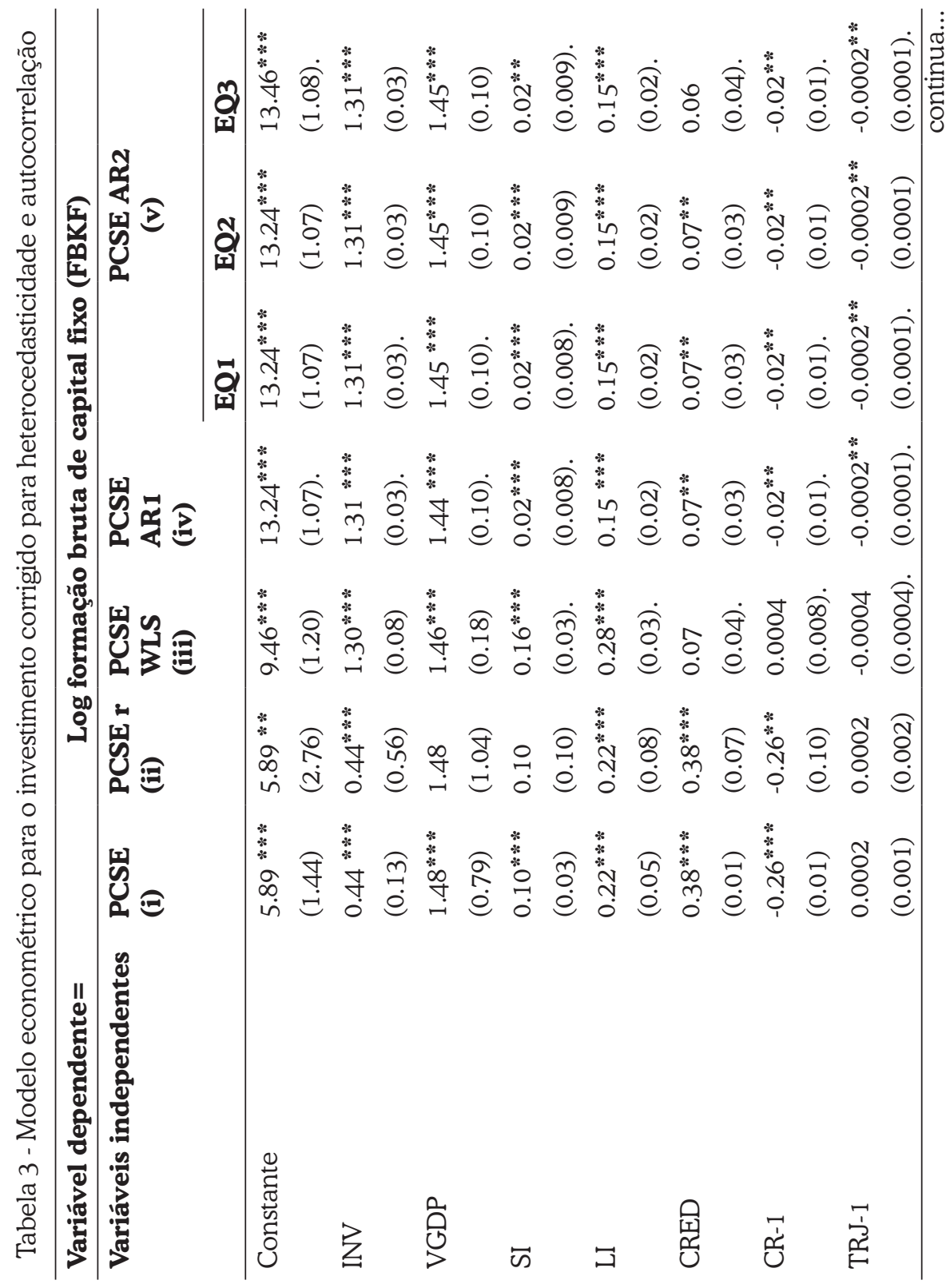




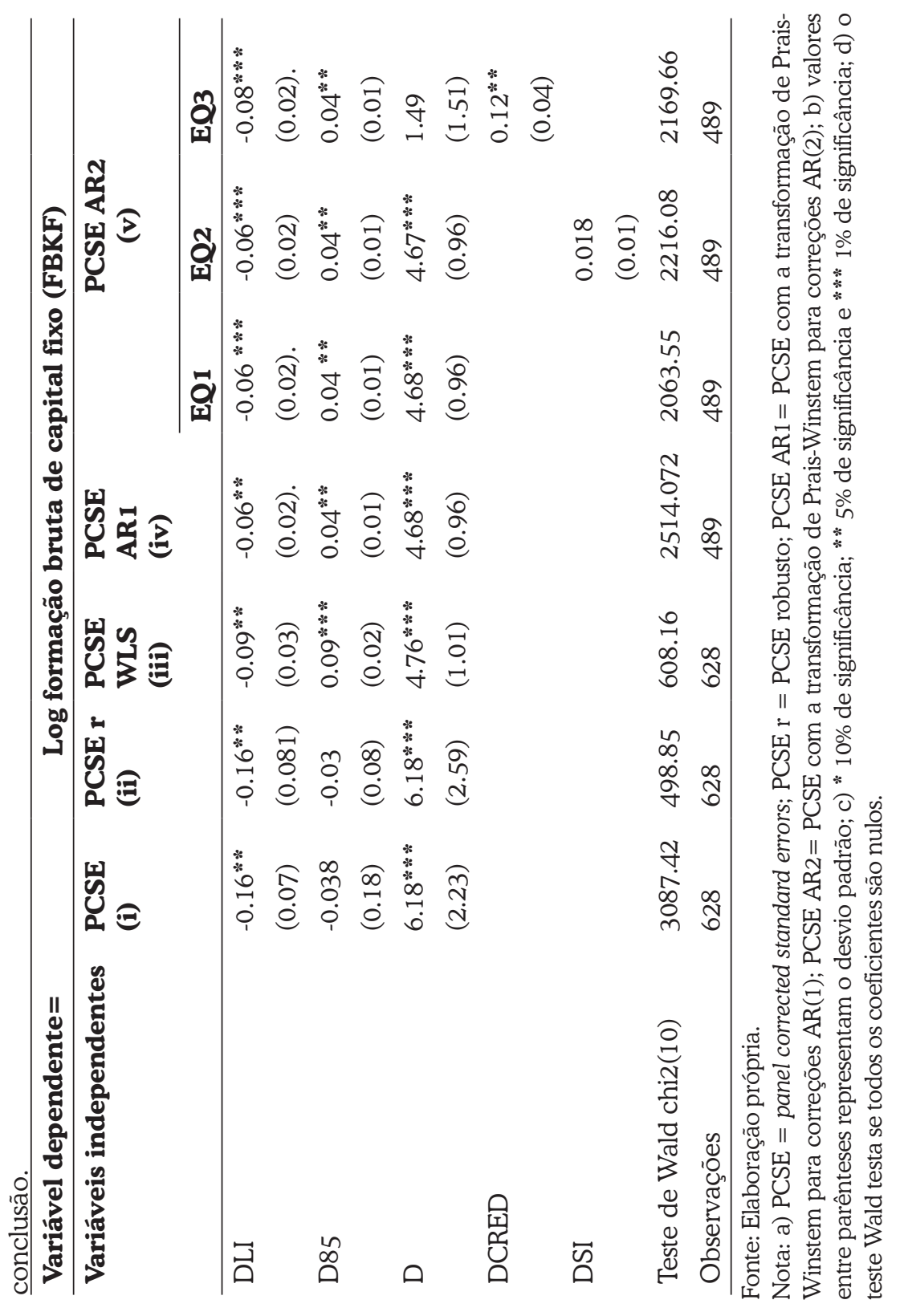




\section{Considerações Finais}

Este artigo procurou identificar os pontos de contato entre a esfera financeira e a esfera real (produtiva e tecnológica) de uma economia, no intuito de desenvolver elementos para se analisar a relação entre liquidez internacional e investimento. Suas principais conclusões são: os resultados das estimações do modelo de investimento confirmaram a relevância das variáveis contempladas na equação 14 para explicar a FBKF. Esse resultado sugere a adequação do modelo desenvolvido e estimado neste trabalho.

Ademais, os resultados das estimações do modelo de investimento corroboram as hipóteses centrais deste trabalho. Ou seja, os ciclos da liquidez internacional afetam a FBKF, e, ainda, a elasticidade do investimento (FBKF) em relação à liquidez internacional é mais elevada para o conjunto de países em desenvolvimento em relação aos países desenvolvidos. Os resultados das estimações atestam, também, a relevância do desenvolvimento relativo do SI para a FBKF, quer para economias desenvolvidas, quer para economias em desenvolvimento.

Finalmente, foram encontradas fortes evidências da existência de restrições de crédito para as economias em desenvolvimento, cujo SI é pouco desenvolvido. A discussão teórica e as evidências empíricas desse ponto sugerem o sistema financeiro como parte integrante do SI. Ou seja, ter desenvolvimento científico e tecnológico implica ter um sistema financeiro desenvolvido e vice-versa.

\section{Referências}

ALBUQUERQUE, E. M. Notas sobre a contribuição de Kenneth Arrow para a fundamentação teórica dos sistemas nacionais de inovações. Revista Brasileira de Economia, v. 50, n. 2, p. 227-242, abr.jun. 1996.

ALVES, J. D. O. E.; LUPORINI, V. Determinantes do investimento privado no Brasil: uma análise de painel setorial. In: ENCONTRO NACIONAL DE ECONOMIA DA ANPEC, 36., 2008, Salvador, Anais... Salvador: ANPEC, 2008.

. Evolução da teoria do investimento e análise empírica para o Brasil. In: ENCONTRO NACIONAL DE ECONOMIA DA ANPEC, 35., 2007, Recife. Anais... Recife: ANPEC, 2007.

AMADO, A. M. Minsky e o ciclo econômico: uma análise para economias periféricas. In: ENCONTRO DE ECONOMIA POLÍTICA, 13., 2003. Florianópolis. Anais... Florianópolis: ANPEC, 2003.

AMADO, A. M.; RESENDE, M. F. C.; JAYME JR, F. G. Economic growth cycles in Latin America and developed countries. In: ENCONTRO NACIONAL DE ECONOMIA DA ANPEC, 35.,. 2007, Recife. Anais... Recife: ANPEC ,2007. 
ARELLANO, M. E.; BOND, S. Some tests of specification for panel data: Monte Carlo evidence and an application to employment equations. Review of Economic Studies, Oxford, v. 58, n. 2, p. 277-297, Apr. 1991.

ARESTIS, P.; GLICKMAN, M. Financial crisis in southeast Asia: dispelling illusion the Minskyan way. Cambridge Journal of Economics. v. 26, n. 2, p. 237-260, march 2002.

BALTAGI, B. H. Econometric analysis of panel data. New York: Wiley. 2001.

BANERJEE, A. Panel data unit roots and cointegration: an overview. Economics and Statistics, Oxford, v. 61, n. 1, p. 607-630, Nov. 1999.

BECK, N. E.; KATZ, J. What to do (and not to do) with time series cross-section data. American Political Science Review, Baltimore, v. 89, n. 3, p. 634-647, Sept. 1995.

BERNARDES, A. T.; ALBUQUERQUE, E. M. Cross-over, thresholds, and interactions Between science and technology: lessons for less-developed countries. Research Policy, v. 32, n. 5 , p. 865-885, dec. 2003.

BOUCEKINE, R. E.; CRUZ, B. Technological progress and investment: microeconomic foundations and macroeconomic implications. Brasília, DF: Ipea, março 2006. (Texto para Discussão, n. 1170).

CABALLERO, R. J. Aggregate investment. In: TAYLOR, J. B.; WOODFORD, M. Handbook of Macroeconomics. North-Holland: Elsevier, 1999. p. 813-862..

CARDOSO, E. O investimento privado na América Latina. Revista de Economia Política, São Paulo, v. 12, n. 4, p. 73-88, out./dez. 1992.

CASTRO, A. S.; CAVALCANTI, M. A. F. H. Estimação de equações de exportação e importação para o Brasil: 1955/95. Rio de Janeiro: IPEA, março 1997. (Texto para Discussão, n. 469).

CHIRINKO, R. S. Business fixed investment spending: modeling strategies, empirical results, and policy implications. Journal of Economic Literature, Nashville, v. 31, n. 4, p. 1875-1911, July 1993.

CRUZ, B. O.; TEIXEIRA, J. R. The impact of public investment on private investment in Brazil, 1947-1990. Cepal Review, Santiago de Chile, n. 67, p. 75-84, Abr. 1999.

DAVIDSON, P. Uncertainty, international money, employment and theory. London: MacMillan,1999. (The collected writings of Paul Davidson, v. 3).

DOW, S.C. Money and the economic process. Aldershot: Edward Elgar, 1993.

. Post Keynesian monetary theory for an open economy. Journal of Post Keynesian Economics, Armonk, v. 9, n. 2, p. 237-257, 1986/1987.

FAGERBERG, J. Technology and international differences in growth rates. Journal of Economic Literature, v. 32, n. 3, p. 1147-1175, Sept. 1994.

FREEMAN, C. The National System of Innovation in historical perspective. Cambridge Journal of Economics, v. 19, n. 1, p. 5-24, Feb. 1995. 
FRISCHTAK, C. R.; CAVALCANTI, M. A. F. H. Incentivos fiscais e investimentos no Brasil: uma análise das mudanças recentes. São Paulo: Iedi, 2005.

GREENE, J.; VILLANUEVA, D. Private investment in developing countries: an empirical analysis. IMF Staff Papers, Washington, D. C., v. 38, n. 1, p. 33-58, Mar. 1991.

HADRI, K. Testing for stationary in heterogeneous panel data. The Econometrics Journal, Oxford, v. 3, n. 2, p.148-161, Dec. 2000.

IM, K. S.; PESARAN, M. H.; SHIN, Y. Testing for unit roots in heterogeneous panels. Journal of Econometrics, Amsterdan, v. 115, n. 1, p. 53-74, July 2003.

INTERNATIONAL MONETARY FUND. International financial statistics (IFS) database. 2007. Disponível em: <www.imfstatistics.org/imf/about.asp>. Acesso em: 15 dez.2007.

JACINTO, P.; RIBEIRO, E. Co-integração, efeitos crowding-in e crowding-out entre investimento público e privado no Brasil: 1973-1989. Teoria e Evidência Econômica, Passo Fundo, v. 6, n. 11, , p. 143-156. nov. 1998.

KEYNES, J. M. A teoria geral do emprego, do juro e da moeda. São Paulo: Nova Cultural, 1983.

. A teoria geral do emprego. In: SZMRECSÁIYI, T. (Org.). Keynes. São Paulo: Àtica, 1999. p. 1-24. Texto publicado originalmente em 1937.

LEVIN, A.; LIN, C.; JAMES CHU, C. S. Unit root tests in panel data: asymptotic and finite sample properties. Journal of Econometrics, Amsterdan, v. 108, n. 1, p. 1-24, May 2002.

MACKINNON, J. G. Critical values for cointegration tests. In: ENGLE, R. F.; GRANGER, C. W. J. (Ed.), Long-run economic relationships: readings in cointegration. Oxford: Oxford University, 1991. p. 1-19.

MADDALA, G. S.; WU, S. A Comparative study of unit root tests with panel data and a new simple test, Oxford Bulletin of Economics and Statistics, v. 61, n. 1, p. 631-652, Nov. 1999.

MÁTYÁS, L. Generalized method of moments. Cambridge: Cambridge University, 1999.

MCCOMBIE, J. S. L.; THIRLWALL, A. P. Economic growth and the balance-of payments constraints. New York: St. Martin's, 1994.

MELO, G. M.; RODRIGUES JÚNIOR, W. Determinantes do investimento privado no Brasil: 1970-1995. Brasília: Ipea, Nov. 1998. (Texto para Discussão, n. 605).

MINSKY, H. P. Integração financeira e política monetária. Economia e Sociedade, Campinas, v. 3, n. 3, p. 21-36, dez. 1994.

. Stabilizing and unstable economy. New Haven: Yale University Press. 1986.

PAULA, L. F. R.; ALVES JÚNIOR, A. J. Fragilidade financeira externa e os limites da política cambial no real. Revista de Economia Política, São Paulo, v. 19, n. 1, p. 72-93, jan./mar. 1999. 
PELICIONI, L. A.; RESENDE, M. F. C. Metas de inflação, política monetária, investimento: um estudo para dezessete países. Revista de Economia Política, São Paulo, v. 29, n. 3, p. 71-92, jul./set. 2009.

RAPOSO, D. A. T. Liquidez internacional e crescimento econômico: uma análise póskeynesiana da experiência mundial. 2009. f. 191. Tese (Doutorado em Economia) - Centro de Desenvolvimento e Planejamento Regional (Cedepar), Universidade Federal de Minas Gerais, Belo Horizonte, 2009.

RESENDE, M. F. C. O Padrão dos ciclos de crescimento da economia brasileira: 1947-2003. Economia e Sociedade, Campinas, v. 14, n. 1, p. 109-129, jan./jun. 2005.

RESENDE, M. F. C.; AMADO, M. A. Liquidez internacional e ciclo reflexo: algumas observações para a América Latina. Revista de Economia Política, São Paulo, v. 27, n. 1, p. 41-59, jan./mar. 2007.

RIBEIRO, M. B; TEIXEIRA, J. R. Na econometric analysis of private-sector investment in Brazil. Cepal Review, Santiago de Chile, v. 74, p. 159-173, ago. 2001.

ROCHA, C.; TEIXEIRA, J. Complementariedade versus substituição entre investimento público e privado na economia brasileira: 1965-90. Revista Brasileira de Economia, Rio de Janeiro, v. 50, n. 3, p. 378-384, jul./set. 1996.

RONCI, M. V. Política econômica e investimento privado no Brasil (1955-82). Rio de Janeiro: FGV, 1991.

RONCI, M. V. Uma nota sobre a especificação da função de investimento agregado para países em desenvolvimento. Revista Brasileira de Economia, Rio de Janeiro, v. 42, n. 2, p. 179-194, abr./jun. 1988.

SACHS, J.; LARRAIN B. F. Macroeconomia: São Paulo: Pearson Makron Books, 2000.

SANTOS, C. H.; PIRES, M. C. C. Qual a sensibilidade dos investimentos privados a aumentos na carga tributária brasileira? Uma investigação econométrica. Brasília, DF: DIRUR/IPEA, 2007.

SERVEN, L.; SOLIMANO, A. Private investment and macroeconomic adjustment: a survey. In: _. (Ed.) Striving for growth after adjustment. Washington, D. C.: The World Bank, 1993. p. 107-146.

SIMONSEN, M. H.; CYSNE, R. P. Macroeconomia. 2. ed. São Paulo: Atlas, 1995.

STUDART, G. Investimento público e formação de capital do setor privado no Brasil: análise empírica da relação de curto e de longo prazos durante o período 1972-1989. 1992. f. 121 Dissertação (Mestrado em Economia) - Programa de pós-graduação em Economia, PUCRIO, Pontíficia Universidade Católica do Rio de Janeiro, Rio de Janeiro, 1992.

UNITED NATIONS CONFERENCE ON TRADE AND DEVELOPMENT. UNCTAD Statistics. 2007. Disponível em: <www.unctad.org/Templates/Page.asp?intItemID $=1584 \mathcal{E}$ lang $=1>$. Acesso em: 15 dez. 2007. 
UNITED STATES PATENT AND TRADEMARK OFFICE. USPTO database. 2007. Disponível em: <www.uspto.gov/main/patents.htm>. Acesso em: dd mm ano.

WOOLDRIDGE, J. M. Econometric Analysis of Cross Section and Panel Data. MIT Press, 2002. Introdução à econometria: uma abordagem moderna. São Paulo: Pioneira Thomson Learning, 2006.

WORLD BANK. World Bank Indicadors Online. Washington, D. C.: Data and Statistic, 2006. Disponível em: <www.publications.worldbank.org > . Acesso em: 15 dez. 2006.

Recebido em: 24/03/13. Aceito em: 22/08/14. 